\title{
Evaluation of personal exposure of workers to indium concentrations in total dust and its respirable fraction at three Japanese indium plants
}

\author{
Ichiro HIGASHIKUBO ${ }^{1 *}$, Heihachiro ARITO ${ }^{1,2}$, Yoko EITAKI ${ }^{1,3}$, Kenji ANDO ${ }^{1}$, \\ Akihiro ARAKI ${ }^{1}$, Hidesuke SHIMIZU ${ }^{1}$ and Haruhiko SAKURAI ${ }^{1}$ \\ ${ }^{1}$ Occupational Health Research and Development Center, Japan Industrial Safety and Health Association, Japan \\ ${ }^{2}$ The Association of Industrial Health, Japan \\ ${ }^{3}$ Department of Preventive Medicine and Public Health, School of Medicine, Keio University, Japan
}

Received May 30, 2018 and accepted July 18, 2018

Published online in J-STAGE August 2, 2018

\begin{abstract}
This study aimed to evaluate personal exposures of 27 workers to indium compounds as "total" dust and its "respirable" fraction in their breathing zones at 3 Japanese indium plants. Eight-hour time-weighted average (TWA) indium concentrations of personal exposure to dust collected in sampling periods of $6 \mathrm{~h}$ or longer were determined by ICP-MS. The arithmetic means of exposure concentrations were $0.095 \mathrm{mg}$ indium $(\mathrm{In}) / \mathrm{m}^{3}$, when sampled as total dust, and $0.059 \mathrm{mg}$ $\mathrm{In} / \mathrm{m}^{3}$, as respirable fraction. ACGIH's TLV-TWA of $0.1 \mathrm{mg} \mathrm{In} / \mathrm{m}^{3}$ for total particulate matter and Acceptable Exposure Concentration Limit (AECL) of $3 \times 10^{-4} \mathrm{mg} \mathrm{In} / \mathrm{m}^{3}$ for the respirable fraction notified by the Japanese Ministry of Health, Labour and Welfare were used to evaluate the exposure concentrations. Twenty-five out of 27 workers were exposed to indium concentrations lower than TLV-TWA, while all of the workers were exposed to the indium concentrations higher than AECL. We noted that there was a large discrepancy between the two occupational exposure limits referred to in this report, and these differences were attributed to the sampling strategies and health effects used as the prevention targets. Carcinogenicity of the respirable fraction of indiumcontaining particulates was considered in setting AECL, whereas it was not in ACGIH's TLV.
\end{abstract}

Key words: Indium, Respirable fraction, Total dust, Particulate matter, Personal sampling, Occupational exposure limit

Occupational exposure to hardly soluble indium particulate matter was reported to have caused the death due to interstitial pneumonia of a male worker engaged in wet surface polishing of indium-tin-oxide (ITO) $)^{1)}$. It is important to protect workers from serious health outcomes due to excessive exposure to indium dust with reference to an occupational exposure limit (OEL). The American

*To whom correspondence should be addressed. E-mail: i-higashikubo@jisha.or.jp

(C)2019 National Institute of Occupational Safety and Health
Conference of Governmental Industrial Hygienists (ACGIH) has recommended a Threshold Limit Value-Time Weighted Average (TLV-TWA) of $0.1 \mathrm{mg}$ indium (In)/ $\mathrm{m}^{3}$ "total" dust $\mathrm{t}^{2)}$. The same $0.1 \mathrm{mg} \mathrm{In} / \mathrm{m}^{3}$ for total dust has been recommended as the Recommended Exposure Limit (REL) by the National Institute for Occupational Safety and Health (NIOSH) ${ }^{3}$. The Japanese Ministry of Health, Labour and Welfare (MHLW) has issued a Technical Guideline ${ }^{4)}$ for Preventing Health Impairment of Workers Engaged in ITO-handling Processes, which designates two occupational standards: an "Acceptable 
Exposure Concentration Limit (AECL) of $3 \times 10^{-4} \mathrm{mg} \mathrm{In} /$ $\mathrm{m}^{3}$ ", and a "Target Concentration (TC) of $0.01 \mathrm{mg} \mathrm{In} / \mathrm{m}^{3 \text { " }}$ as the respirable fraction of indium particulate matter. The AECL value could be surrogated as a putative OEL for the respirable fraction of indium particulate matter, provided that the dust is collected in workers' breathing zones as the respirable fraction ${ }^{2)}$ in a sampling period of $6 \mathrm{~h}$ or longer ${ }^{5)}$. At least, two different methods of collection of airborne indium particulate matter have been used: "total" dust as "particulates not otherwise regulated, total" as designated by the NIOSH sampling method ${ }^{6}$, and "respirable" dust as a particle size-selective sampling criterion of airborne particulate matter ${ }^{2}$. Our previous study ${ }^{7)}$, a quantitative assessment of the personal exposures of 86 workers to "total" indium dust at 11 plants revealed that 11 workers were exposed to concentrations of total dust that were higher than the TLV-TWA, and that 8 indium plants were evaluated as requiring "control measures" for the indiumhandling operations.

The present study assessed the personal exposures of individual workers to indium particulate matter collected as "total" dust and its "respirable" fraction at 3 Japanese indium plants with reference to the 2 different OELs, the TLV-TWA ${ }^{2)}$ and the putative OEL-TWA. We also examined the adequacy of the industrial hygiene control measures implemented at the 3 plants.

Three plants were chosen from among 38 indiumhandling companies in Japan with annual production of indium exceeding $500 \mathrm{~kg}$ in 2009 . We recruited a total of 27 workers from the 3 plants. Seventeen workers were engaged in various indium-manufacturing operations in Plant i. Eight workers in Plant $\mathrm{j}$ and 2 workers in Plant $\mathrm{k}$ specialized in recycling/reclamation operations. The 27 workers were asked to wear a personal sampling holder at their breathing zone to collect "total" dust and its "respirable" fraction for a sampling period of $6 \mathrm{~h}$ or longer.

"Total" dust was collected as "particulates not otherwise regulated, total" as designated by the NIOSH method ${ }^{6)}$. The total dust was collected on a mixed cellulose ester membrane filter $(0.8-\mu \mathrm{m}$ pore size, $37-\mathrm{mm}$ diameter, Japan Millipore, Co.) in a cassette filter holder (SKC Inc.) at a flow rate of $1.0 \mathrm{l} / \mathrm{min}$, using a portable suction pump (Aircheck 2000, SKC, Inc). "Respirable" dust was collected by a sampler with a size selection capability to capture airborne particulate matter having a $50 \%$ cut point at $4 \mu \mathrm{m}$ in accordance with the ACGIH's sampling method ${ }^{2)}$ and MHLW's Technical Guideline ${ }^{4)}$. The respirable fraction of dust was collected on a mixed cellulose ester membrane filter $(0.8-\mu \mathrm{m}$ pore size, $37-\mathrm{mm}$ diameter, Japan Millipore,
Co.) in a cassette filter holder (SKC, Inc.) at a flow rate of $2.75 \mathrm{l} / \mathrm{min}$, using a respirable dust cyclone (GS-3, SKC, Inc.). The 8-h (8h)-TWA of indium concentration of personal exposures to total and respirable dust were calculated using the following equation:

8h-TWA $=(\mathrm{Cpi} \times \mathrm{Tpi}) / 8 \mathrm{~h}$,

where Cpi $\left(\mathrm{mg} / \mathrm{m}^{3}\right)$ and Tpi $(\mathrm{h})$ indicate the observed indium concentrations of exposure to total or respirable dust, and the period of time used for sampling indium dust, respectively. We calculated the ratios of the indium concentrations of exposure to the total dust (TD) to those of its respirable fractions (RD).

The analysis of indium was carried out by an Inductively Coupled Plasma-Mass Spectrometer (ICP-MS) (Agilent7500i, Agilent Technology, Japan) using the modified method described in our previous study ${ }^{7}$.

In addition to conventional statistical indices, the upper 95th percentile of the log-normal distribution $\left(\mathrm{X}_{95}\right)$ was calculated using following equation:

$\log \left(\mathrm{X}_{95}\right)=\log (\mathrm{GM})+1.65 \times \log (\mathrm{GSD})$.

We used OEL $<\mathrm{X}_{95}$ to define "control measures required" for each plant, followed the method described by the NIOSH Manual ${ }^{5)}$, and Bullock and Ignacio ${ }^{8)}$. We also compared the indium concentrations of individual workers with the Action level $(\mathrm{AL})^{5)}$ which is defined by NIOSH as one-half of the REL $\left(0.05 \mathrm{mg} \mathrm{In} / \mathrm{m}^{3}\right)$. When the indium plant had less than 5 workers, we defined "control measures required" using either AL as one-half of ACGIH's TLV or NIOSH's REL $<$ Maximum (Max) of the exposure concentrations, or TLV or REL $<$ Arithmetic mean (AM) of the exposure concentrations.

Total dust and its respirable fraction: Table 1 shows the personal exposures of the 27 workers to indium concentrations in total dust and its respirable fraction in the breathing zone at the 3 plants. The AM indium concentration of all the workers was $0.095 \mathrm{mg}$ indium $/ \mathrm{m}^{3}$ as total dust, and ranged from $0.00040 \mathrm{mg} \mathrm{In} / \mathrm{m}^{3}$ to $1.27 \mathrm{mg} \mathrm{In} /$ $\mathrm{m}^{3}$. There were two workers whose indium concentrations of exposure to total dust exceeded the TLV-TWA. The AM indium concentration was $0.05889 \mathrm{mg} \mathrm{In} / \mathrm{m}^{3}$ as the respirable fraction, indicating that the $\mathrm{AM}$ value of exposure to the respirable fraction was about $60 \%$ of exposure to total dust. The TD/RD ratios of AM at Plants $\mathrm{j}$ and $\mathrm{k}$ were small in comparison with large AM ratio at Plant $i$ and they ranged from 1.01 to 15.31. A worker employed in the ITO powder-pressing operation at Plant i was exposed to coarse particulate matter as evidenced by a large $\mathrm{TD} / \mathrm{RD}$ ratio 
Table 1. Indium concentrations determined as personal exposures to total dust and its respirable fraction in workers' breathing zones at three indium plants, $i, j$ and $k$, and the ratios of the indium concentrations of total dust (TD) to the respirable fraction (RD)

\begin{tabular}{|c|c|c|c|c|c|c|c|c|c|}
\hline Items & Plants & $\begin{array}{c}\text { Number of } \\
\text { indium-exposed } \\
\text { workers }\end{array}$ & $\begin{array}{c}* \text { Number of } \\
\text { workers whose } \\
\text { exposure } \\
\text { exceeded the } \\
\text { TLV-TWA or } \\
\text { the putative } \\
\text { OEL-TWA }\end{array}$ & $\begin{array}{c}\operatorname{Min} \\
\left(\mathrm{mg} \mathrm{In} / \mathrm{m}^{3}\right)\end{array}$ & $\begin{array}{c}\operatorname{Max} \\
\left(\mathrm{mg} \mathrm{In} / \mathrm{m}^{3}\right)\end{array}$ & $\begin{array}{c}\mathrm{AM} \\
\left(\mathrm{mg} \mathrm{In} / \mathrm{m}^{3}\right)\end{array}$ & $\begin{array}{c}\mathrm{GM} \\
\left(\mathrm{mg} \mathrm{In} / \mathrm{m}^{3}\right)\end{array}$ & GSD & $\begin{array}{c}\text { The upper } 95 \text { th } \\
\text { percentile of } \\
\text { a log normal } \\
\text { distribution } \\
\left(\mathrm{mg} \mathrm{In} / \mathrm{m}^{3}\right)\end{array}$ \\
\hline \multirow{4}{*}{$\begin{array}{l}\text { Indium } \\
\text { concentrations } \\
\text { of total dust }\end{array}$} & $\mathrm{i}$ & 17 & 1 & 0.0004 & 0.96 & 0.071 & 0.0097 & 6.67 & 0.220 \\
\hline & $\mathrm{j}$ & 8 & 0 & 0.0011 & 0.026 & 0.0086 & 0.0045 & 3.50 & 0.035 \\
\hline & $\mathrm{k}$ & 2 & 1 & 0.0025 & 1.27 & 0.638 & $\mathrm{NC}$ & $\mathrm{NC}$ & $\mathrm{NC}$ \\
\hline & Total & 27 & 2 & 0.0004 & 1.27 & 0.095 & 0.009 & 7.02 & 0.217 \\
\hline \multirow{4}{*}{$\begin{array}{l}\text { Indium } \\
\text { concentrations } \\
\text { of the respirable } \\
\text { fraction }\end{array}$} & $\mathrm{i}$ & 17 & 17 & 0.00038 & 0.57 & 0.0415 & 0.00563 & 5.74 & 0.100 \\
\hline & $\mathrm{j}$ & 8 & 8 & 0.00099 & 0.025 & 0.0082 & 0.00409 & 3.65 & 0.0344 \\
\hline & $\mathrm{k}$ & 2 & 2 & 0.0023 & 0.82 & 0.410 & $\mathrm{NC}$ & $\mathrm{NC}$ & $\mathrm{NC}$ \\
\hline & Total & 27 & 27 & 0.00038 & 0.82 & 0.0589 & 0.00595 & 6.23 & 0.121 \\
\hline Items & Plants & $\mathrm{N}$ & - & Min & Max & $\mathrm{AM}$ & GM & GSD & $\begin{array}{c}\text { The upper } 95 \text { th } \\
\text { percentile }\end{array}$ \\
\hline \multirow[t]{4}{*}{ Ratios of TD to RD } & $\mathrm{i}$ & 17 & - & 1.01 & 15.3 & 2.64 & 1.48 & 2.15 & 9.28 \\
\hline & $\mathrm{j}$ & 8 & - & 1.01 & 1.29 & 1.11 & 1.01 & 1.10 & 1.28 \\
\hline & $\mathrm{k}$ & 2 & - & 1.08 & 1.56 & 1.32 & $\mathrm{NC}$ & $\mathrm{NC}$ & $\mathrm{NC}$ \\
\hline & Total & 27 & - & 1.01 & 15.3 & 2.09 & 1.28 & 1.89 & 5.96 \\
\hline
\end{tabular}

Min; Minimum value; MAX: Maximum value; AM: Arithmetic mean; GM: Geometric mean; GSD: Geometric standard deviation; NC: Not Calculated. *ACGIH'sTLV-TWA is $0.1 \mathrm{mg} \mathrm{In} / \mathrm{m}^{3}$ total dust, while the putative OEL-TWA is $3 \times 10^{-4} \mathrm{mg} \mathrm{In} / \mathrm{m}^{3}$ respirable dust.

(15.31). Another worker employed in the ingot-sintering operation at Plant $\mathrm{j}$ was exposed to a respirable fraction of enriched indium dust as evidenced by a low $\mathrm{TD} / \mathrm{RD}$ ratio (1.01).

$\mathrm{X}_{95}$ was used to judge whether or not the indium plants required "control measures". Using the condition ${ }^{5,8)}$ $\mathrm{TLV}<\mathrm{X}_{95}$, Plants $\mathrm{i}$ and $\mathrm{j}$ were assessed as requiring "control measures required". Plant $k$, with less than 5 workers, was also assessed as requiring "control measures" using the condition TLV $<\mathrm{AM}$. According to the condition of OEL (AECL surrogated as OEL) $<\mathrm{X}_{95}$, Plants $i$ and $j$ were assessed as requiring "control measures". Plant $\mathrm{k}$ was also assessed as requiring "control measures" using the condition OEL (AECL surrogated as OEL) $<\mathrm{AM}$.

As shown in Table 2, Worker i17 was exposed to a very high indium concentration of $0.96 \mathrm{mg} \mathrm{In} / \mathrm{m}^{3}$ total dust in the cutting-off and crushing operations of ITO targets. Worker $\mathrm{k} 2$ was exposed to a high indium concentration of $1.27 \mathrm{mg} \mathrm{In} / \mathrm{m}^{3}$ total dust in the crushing and shotblasting operations. These 2 workers wore half-face dust masks with an assigned protection factor (APF) of 10 and handled indium materials under fixed capture, circular, hood-type, local exhaust ventilation (LEV) with an air velocity of $0.1 \mathrm{~m} / \mathrm{s}$ at the capture point. We recommended their employers to provide the workers with powered airpurifying respirators (PAPR) and to implement more stringent engineering control measures such as containment or an enclosed type LEV. Liu et al. have reported the high efficacy of implementing PAPR in the reduction of ITO workers' indium exposures ${ }^{9)}$. Containment and enclosed hood-type LEVs have been reported to reduce the exposure concentration to $1 / 100$ of that of general ventilation $(\mathrm{GV})^{10)}$.

All workers' indium concentrations of the respirable fraction of dust collected in a sampling period of $6 \mathrm{~h}$ or longer were found to exceed the putative OEL-TWA. Twenty-one out of the 27 workers were performing indium-handling operations in workplaces equipped with hood-type LEVs. Worker i9 was engaged in the dusty operation of grinding and cutting off of indium phosphide (InP) within a glove box, while he only wore a disposable, unwoven mask. Nevertheless, his exposure to indium was only $0.00038 \mathrm{mg} \mathrm{In} / \mathrm{m}^{3}$, which was only marginally higher than the putative OEL-TWA. We recommended his employer to provide workers with a full facepiece, powered, air-purifying respirator with an APF of 1,000 according to the OSHA Standard ${ }^{11)}$, or full-face respiratory protective equipment (RPE) with an electric fan and an APF of 


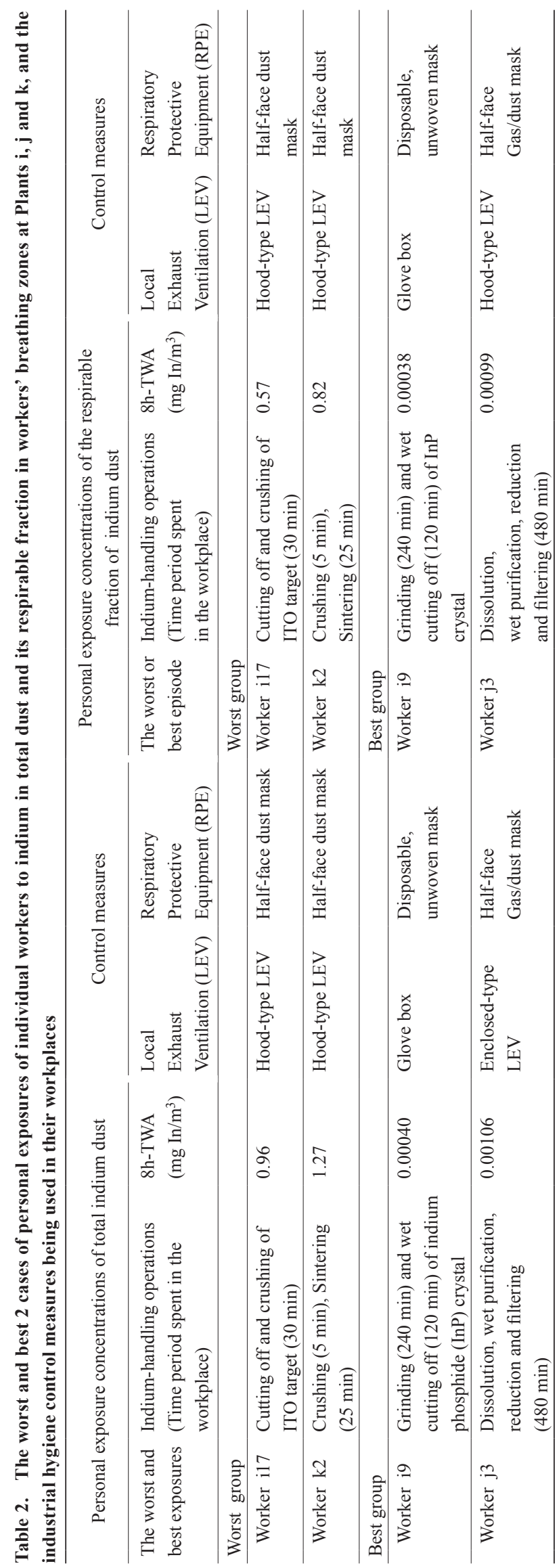


50-100 in accordance with the Technical Guideline ${ }^{4)}$.

It was found, in the present study, that all the workers in the 3 plants were exposed to higher respirabe fraction indium concentrations than the putative OEL, in sharp contrast to the personal exposures of almost all workers $(25 / 27)$ to total dust indium concentrations, which were below the TLV-TWA. This difference can be attributed to two causative factors on which these two OEL values are based. ACGIH's recommendation of the TLV-TWA for total indium dust is based on the skeletal and gastrointestinal effects, and pulmonary toxicity associated with inhaled indium without notations of carcinogenicity ${ }^{2,12)}$. The Technical Guideline's AECL ${ }^{3)}$ of $3 \times 10^{-4} \mathrm{mg} \mathrm{In} / \mathrm{m}^{3}$ is based on the empirical dose-response relationship between the inhalation exposure concentrations of respirable ITO dust and the increased incidences of lung cancer reported in a $2 \mathrm{yr}$ inhalation carcinogenicity study of rats ${ }^{4)}$. Another factor is difference in the collection of airborne indium particulate matter between total dust and its respirable fraction. The AECL and TC have only been used for the legislative evaluation of indium-contaminated workplace air which is conducted by area sampling of the respirable fraction of indium dust. In these evaluations, respirable indium dust is collected at 5 or more measuring points per workplace in short sampling periods of $10 \mathrm{~min}$ or longer ${ }^{4}$. Besides, the Technical Guideline's method ${ }^{4)}$ for the evaluation of indium-contaminated work environments by area sampling is entirely different from the assessment of personal exposures to indium particulate matter in workers' breathing zones. Therefore, we suggest that the Technical Guideline's AECL of $3 \times 10^{-4} \mathrm{mg} \mathrm{In} / \mathrm{m}^{3}$ can be surrogated as the putative OEL-TWA, provided that airborne indium particulate matter is collected as the respirable fraction ${ }^{2)}$ in workers' breathing zones using sampling periods of $6 \mathrm{~h}$ or longer. Cummings et al. ${ }^{13)}$ suggested that indium particulate matter with a mass median aerodynamic diameter smaller than $4 \mu \mathrm{m}$ can penetrate into the alveolar region when inhaled, and would be toxicologically relevant for chronic respiratory diseases and lung cancer. The present finding of low TD/RD ratios in the 2 indium recycling/ reclamation plants in contrast to the high ratio of 15.31 (Max) in the plant manufacturing electronic devices can be interpreted as being caused by enriched respirable fractions of airborne indium particulate matter in the two recycling plants, which were more hazardous than in the other plant. Further study will be needed to establish an internationally recognized OEL value for indium particulate matter with carcinogenic potential, and to examine not only particle size-selective sampling criteria, but also the particle size distributions of airborne indium particulate matter to which workers are exposed by inhalation during working hours.

In conclusion, the personal exposures of 27 workers to indium concentrations of total dust and its respirable fraction in their' breathing zones at 3 Japanese indium plants was evaluated, using the TLV-TWA for total dust and the putative OEL for the respirable fraction. Twenty-five out of 27 workers were exposed to indium concentrations lower than the TLV-TWA, whereas all of the workers were exposed to indium concentrations higher than the putative OEL. This large difference was attributed to the OELs, with or without consideration of the carcinogenic potential, and the particle sizes of indium dust measured as total dust or its respirable fraction. The efficiencies of the LEV and RPE used at the 3 plants were investigated for the mitigation of personal exposures to indium dust.

\section{Conflict of Interest}

The authors declare that they have no conflicts of interest.

\section{References}

1) Homma $T$, Ueno $T$, Sekizawa $K$, Tanaka A, Hirata M (2003) Interstitial pneumonia developed in a worker dealing with particles containing indium-tin oxide. J Occup Health 45, 137-9. [Medline] [CrossRef]

2) American Conference of Governmental Industrial Hygiene (ACGIH) (2017) TLVs and BEIs based on the Documentation of the Threshold Limit Values for Chemical Substances and Physical Agents \& Biological Exposure Indices. ACGIH, Cincinnati.

3) The National Institute for Occupational Safety and Health (NIOSH) NIOSH Pocket Guide to Chemical Hazards. Indium Compounds. NIOSH, Cincinnati, OH, USA. https:// www.cdc.gov/niosh/npg/npgd0341.html. Accessed March 5, 2018.

4) Japan Ministry of Health, Labour and Welfare (MHLW) (2010) The Technical Guideline for Preventing Health Impairment of Workers Engaged in the Indium Tin oxide Handling Processes issued on December 22, 2010 as the Notification of Labour Standards Bureau No.1222-3 by MHLW, Bureau of Labor Standards, Division of Industrial Safety and Health, Tokyo.

5) National Institute for Occupational Safety and Health (NIOSH) (1977) Occupational Exposure Sampling Strategy Manual. DHEW (NIOSH) Publication No. 77-173. January 1977. US. Department of Health, Education and Welfare, Public Health Service, Center for Disease Control, NIOSH, Cincinnati.

6) National Institute for Occupational Health (NIOSH) (1994) 
NIOSH Manual for Analytical Methods No.0500 Issue 2 (15 August 1994) Particulates not otherwise regulated, total. https://www.cdc.gov/niosh/docs/2003-154/pdfs/7301.pdf. Accessed May 1, 2018.

7) Higashikubo I, Arito H, Eitaki Y, Araki A, Ando K, Shimizu H, Sakurai H (2018) Quantitative assessment of occupational exposure to total indium dust in Japanese indium plants. Ind Health 56, 553-60. [Medline] [CrossRef]

8) Bullock WH, Ignacio JS (2006) A strategy for assessing and managing occupational exposures, 3rd Ed. American Industrial Hygiene Association, Fairfax.

9) Liu HH, Chen CY, Lan CH, Chang CP, Peng CY (2016) Effects of a powered air-purifying respirator intervention on indium exposure reduction and indium related biomarkers among ITO sputter target manufacturing workers. J Occup Environ Hyg 13, 346-55. [Medline] [CrossRef]

10) Health and Safety Executive (HSE) UK. The Control of
Substances Hazardous to Health (COSHH) Essentials: Controlling Exposure to Chemicals. A Simple Control Banding Approach. http://www.hse.gov.uk/pubns/guidance/ coshh-technical-basis.pdf. Accessed March 29, 2018.

11) US Occupational Safety and Health Administration (OSHA) (2009) OSHA Assigned Protection Factors for Revised Respiratory Protection Standard. OSHA, Department of Labor, Washington DC.

12) American Conference of Governmental Industrial Hygienists (ACGIH) (2001) Indium and Compounds. In: Documentation of the Threshold Limit Values (TLVs) and Biological Exposure Indices (BEIs). ACGIH, Cincinnati.

13) Cummings KJ, Virji MA, Park JY, Stanton ML, Edwards NT, Trapnell BC, Carey B, Stefaniak AB, Kreiss K (2016) Respirable indium exposures, plasma indium, and respiratory health among indium-tin oxide (ITO) workers. Am J Ind Med 59, 522-31. [Medline] [CrossRef] 